' Hegmann, J. P., and DeFries, J. C., Psychon. Sci., 13, 27 (1988).

4 Thompson, W. R., in Behavior-Genetic Analysis (edit. by Hirsch, J.) (McGraw-Hill, New York, 1967).

s Thompson, W. R., in Handbook of Multivariate Experimental Psychology (edit. by (atteli, R. B.) (Rand MoNally, Chicago, 1966).

- Loehlin, J. C., and Vandenberg, S. G., in Progress in Human Behavioral Geretics (edit. by Vandenberg, S. G.) (Johns Hopkins Press, Baltimore, 1968).

'Smith, C., King, J. W. B., and Gilbert, N., Anim. Prod., 4, 128 (1062).

\section{Dislocation of Tones in a Musical Sequence: a Memory Illusion}

Computer-gentrated tonal soquoncos have several advantages for investigations of immediate memory: the stimulus parameters are simple and can be exactly controlled, and the items cannot be readily rehearsed. Previous studies of memory for pitch have investigated the effect on the differcntial throshold of blank intervals between the standard and comparison tones ${ }^{1-3}$ and of one interpolated ton $e^{4, \overline{0}}$.

In tho recognition of sirmple musical sequences the order of the component tones is usually supposed to be well rotaincd; and this assumption is espccially important to musical analyses based on information theory ${ }^{6}$. I have, however, found that there can be a rapid loss of such order information in a very simple tonal sequence; namoly, the traditional musical scale.

The procedure was as follows. A subject listened to a test tone, which was followed by a sequence of four intervening tones and, after a pause, by a probe tone. The subject was instructed to try to remember the test tone, ignore the four intervening tones if he wished, and thon to judgo whether the probe tono was or was not of the same pitch as the tost tone. All tones lasted for $200 \mathrm{~ms}$. The first five tones were separated by intervals of $300 \mathrm{~ms}$, and there was a 2 s pause before the probe tone (see Fig. 1). The tones were all equally loud and taken from an equaltempered scale $(A=435)$ ranging just over an octave, from middle $\mathrm{C}$ to the $\mathrm{C} \#$ an octave above. When the test and probe tones differed in pitch, the difference was always a semitone (higher in half the instancos, and lower in tho other half): this is well above the recognition. threshold in the absence of intervening tones, even with much longer delays between test and probe ${ }^{1-3}$. The intervening tones wore chosen randomly except that no sequence contained repeated tones unless they were

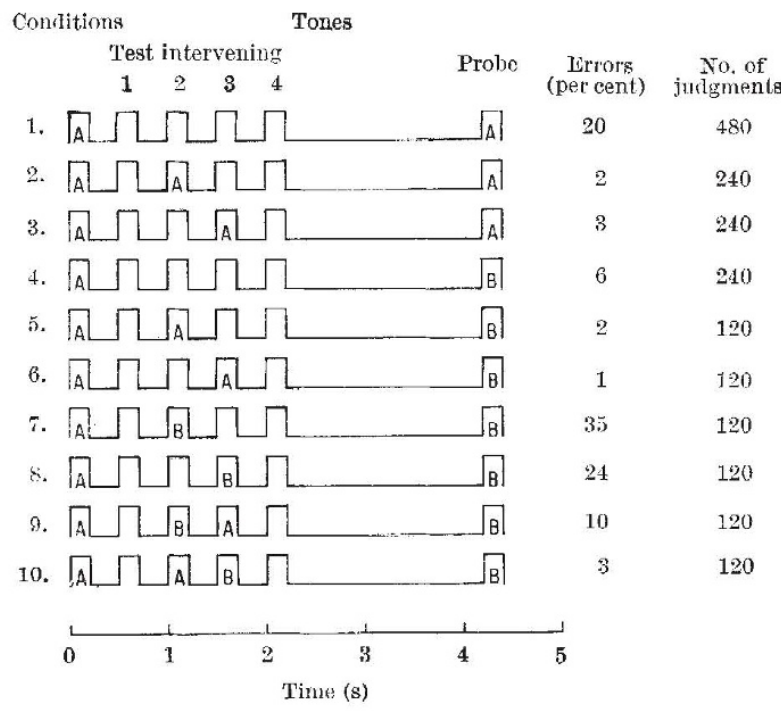

Fig. 1. Arrangement of tonal sequerces in the different exporimental conditions. with number of judgments and percentage of errors made in specified by the experimental conditions. All the test and probe tone pitches were equally represented in all conditions.

Tones were generated by a Wavetek oscillator controlled by a PDP9 computer, and wore recorded on tape. Subjects were selected on the basis of obtaining a score of at least 80 per cent correct on a short tape containing similar sequences. The data froxn the lwo days of the experiment were averaged.

The experiment investigated the effect on rocognition memory of inserting, in tho intervening soquence, tones of the same pitch as the test and probo tones. The different, experimental conditions are shown in Fig. 1. Here, $A$ represents the piteh of the test tone, and of the probe tone when the two are identical. $B$ represents the pitch of the probe tone when it differs from $A$. The results (Fig. 1) show that insertion in the intervening sequence of a tone at the same pitch as the probe tome has a striking effect. Whon, the test and probe tones differ in pitch, and neither of these pitches is included in the intervening sequence, errors are only 6 per cent, (condition 4). Errors increase to 24 per cent with insertion in the third serial position of the intervening sequence of a tone at the same pitch as the probe tone (condition 8); and to 35 per cent with insortion in the scoond serial position (condition 7). This effect is significant on a sign test at the 0.01 level. Further, whon the test and probe tones are identical in piteh, insortion in the intervening sequence of a tone at that pitch causes a dramatic reduction in errors ( 2 per cent and 3 per cent in conditions 2 and 3 respectively, compared with 20 per cent in condition 1 ). This is also significant on a sign tost at the 0.01 level.

I propose that subjects showed an increased tendency to err in conditions 7 and 8 because, although they correctly recognized that the probe tone pitch had occurred, they were unable to localize it correctly in the intervening sequence. The same loss of order information could also account for the increased tendency to judge the test and probe tones as the samc in conditions 2 and 3 (although the latter finding could result from a trace strengthening effect of repeating the test tone); and this consideration might also be appliod to the decreased number of errors when both the test and probe tone pitches aro included in the intervening sequence (conditions 9 and 10) rather than the probo tone pitch alone (conditions 7 and 8).

Tt might be thought that the subjects did not initially hear the sequences correetly; but in a control experiment the identical sequencos were played, with the probe tone 2 s before the test tone, and the subjects had no difficulty in making correct judgments.

The conclusion that memory for tonal ordor deteriorates rapidly, evon in the traditional musical scale, can be reconciled with the unquestionable importance of order in tuno recognition by assuming that we process tonal information on the basis of higher-ordor attributes ${ }^{7}$ and rapidly discard absolute pitch information.

The preparation of this communication was supported in part by the US Public Hcalth Service and the US National Scionce Foundation. I thank G. Mandler for support and discussions, and N. H. Anderson, D. Green and D. Rumelhart for comments.

Departmont of Psychology,

Diana DeUtsch

University of California,

San Diego, PO Box 109,

La Jolla, California 92037.

Reveived October 27, 1969; revised February 2, 1970.

${ }^{1}$ Koester. T., Areh. Psychol., 41, No, 297 (1945).

${ }^{2}$ Harris, J, D, J. Exp. Psychol., 43, 96 (1952).

3 Konig, E., J. Acoust. Soc. A mer., 29, 606 (1957).

4 Postman, L., Amer., J. Psychol., 59, 193 (1948).

8 Wickelgren, W. A., J. Exp, Psychot., '72, 259 (1960); J. Math. Psychol., 6, 13 (1969).

${ }^{6}$ Cohen, J. F., Behavioral Science, 7, 137 (1962).

? Deutsch, D., Psychol. Review, 76, 300 (1969). 